\title{
Design of Robust PI Controller for Counter-Current Tubular Heat Exchangers
}

\author{
Jana Závacká, Monika Bakošová \\ Institute of Information Engineering, Automation and Mathematics, \\ Faculty of Chemical and Food Technology, STU in Bratislava, \\ Radlinského 9, 81237 Bratislava, Slovakia \\ jana.zavacka@stuba.sk
}

\begin{abstract}
The paper presents an approach for robust PI controller design for a system affected by parametric uncertainty. The method is based on plotting the stability boundary locus in the plane of controller parameters that is called $\left(k_{p}, k_{i}\right)$-plane. Designed robust PI controller is implemented for control of two counter-current tubular heat exchangers in series with uncertain parameters, in which kerosene as a product of distillation in a refinery has to be cooled by water. The controlled variable is the temperature of the outlet stream of the kerosene from the second heat exchanger and the control input is the volumetric flow rate of the inlet stream of the cold water in the second heat exchanger. Simulation results of robust PI control of heat exchangers are also presented.
\end{abstract}

Keywords: interval uncertainty, robust control, robust PI controller, tubular heat exchangers

\section{Introduction}

Heat exchangers belong to the standard equipment in the chemical and food industries. In the food industry various models have been suggested for the prediction of fouling thickness and milk outlet temperature in a heat exchanger (Nema and Datta 2006). Control of the outlet temperature of a counter-current tubular heat exchanger by the predictive functional control is shown in Abaoui et al. 2007. A boundary geometric control strategy is proposed to control the internal fluid temperature at the outlet of a counter-current heat exchanger by manipulating the inlet external fluid temperature (Maidi et al. 2009).

This paper presents a method for design of robust PI controllers for two counter-current tubular heat exchangers in series. The method is based on plotting the stability boundary locus in the $\left(k_{p}\right.$, $k_{i}$ )-plane. The parameters of a stabilizing PI controller are determined from the stability region (Söylemez et al. 2003). The robust PI controller stabilizes a controlled system with interval parametric uncertainties, when the stability region is found for sufficient number of Kharitonov plants (Barmish 1994).
Two counter-current tubular heat exchangers in series are considered as a controlled system with two uncertain parameters, in which kerosene as a product of the distillation in a refinery has to be cooled. Kerosene flows in the inner tubes and the cooling water is in the shell of the heat exchangers. Designed robust PI controller was implemented for control of counter-current tubular heat exchangers and this paper presents simulations results.

\section{Theoretical}

\section{Robust PI Controller Design}

Consider the single-input single-output (SISO) control system shown in Fig. 1

Here $w$ is the set point, $e$ is the control error, $u$ is the control input and $y$ is the controlled output. The controlled process is described by the transfer function

$$
G(s, b, a)=\frac{N(s, b)}{D(s, a)}
$$

where $b, a$ are vectors of uncertain parameters and $N, D$ are polynomials in $s$ with coefficients, which depend on $b, a . C(s)$ is the transfer function of a PI controller in the form

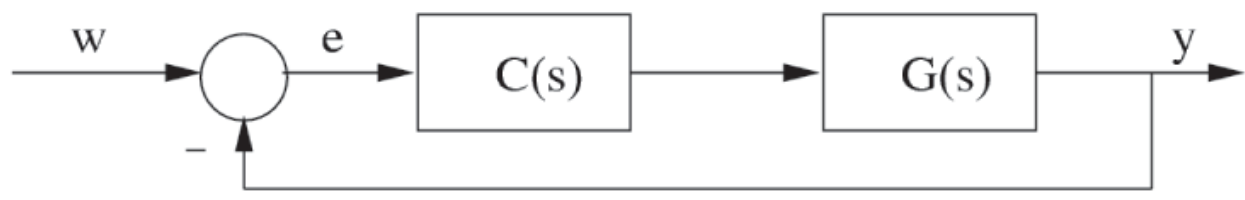

Fig. 1. Control system. 


$$
C(s)=k_{p}+\frac{k_{i}}{s}=\frac{k_{p} s+k_{i}}{s}
$$

The task is to find the parameters $k_{p}, k_{i}$ of the PI controller (2) that stabilize the system in Figure 1.

\section{PI Controller Design}

Decomposing the numerator and the denominator polynomials of (1) into their even $\left(_{\mathrm{e}}\right)$ and odd $\left(_{\mathrm{o}}\right)$ parts, and substituting $s=j \omega$, where $\omega$ is the frequency (Tan and Kaya 2003, Závacká et al. 2008), gives

$$
G(j \omega)=\frac{N_{e}\left(-\omega^{2}\right)+j \omega N_{o}\left(-\omega^{2}\right)}{D_{e}\left(-\omega^{2}\right)+j \omega D_{o}\left(-\omega^{2}\right)}
$$

The closed-loop characteristic equation is in the form

$$
\begin{gathered}
\Delta(j \omega)= \\
=\left[k_{i} N_{e}\left(-\omega^{2}\right)-k_{p} \omega^{2} N_{o}\left(-\omega^{2}\right)-\omega^{2} D_{o}\left(-\omega^{2}\right)\right]+ \\
+j\left[k_{p} \omega N_{e}\left(-\omega^{2}\right)+k_{i} \omega N_{o}\left(-\omega^{2}\right)+\omega D_{e}\left(-\omega^{2}\right)\right]=0
\end{gathered}
$$

Equating the real and imaginary parts of $\Delta(j \omega)$ to zero gives

$$
k_{p}\left(-\omega^{2} N_{o}\left(-\omega^{2}\right)\right)+k_{i}\left(N_{e}\left(-\omega^{2}\right)\right)=\omega^{2} D_{o}\left(-\omega^{2}\right)
$$

and

$$
k_{p}\left(N_{e}\left(-\omega^{2}\right)\right)+k_{i}\left(N_{o}\left(-\omega^{2}\right)\right)=D_{e}\left(-\omega^{2}\right)
$$

After defining

$$
\begin{gathered}
F(\omega)=-\omega^{2} N_{o}\left(-\omega^{2}\right) \\
G(\omega)=N_{e}\left(-\omega^{2}\right) \\
H(\omega)=\omega^{2} D_{o}\left(-\omega^{2}\right) \\
I(\omega)=N_{e}\left(-\omega^{2}\right) \\
J(\omega)=N_{o}\left(-\omega^{2}\right) \\
K(\omega)=-D_{e}\left(-\omega^{2}\right)
\end{gathered}
$$

(5) and (6) can be written as

$$
\begin{gathered}
k_{p} F(\omega)+k_{i} G(\omega)=H(\omega) \\
k_{p} I(\omega)+k_{i} J(\omega)=K(\omega)
\end{gathered}
$$

From (8), parameters of the PI controller (2) are

$$
k_{p}=\frac{H(\omega) J(\omega)-K(\omega) G(\omega)}{F(\omega) J(\omega)-G(\omega) I(\omega)}
$$

and

$$
k_{i}=\frac{K(\omega) F(\omega)-H(\omega) I(\omega)}{F(\omega) J(\omega)-G(\omega) I(\omega)}
$$

Solving these two equations simultaneously for $\omega \geq 0$, the set of parameters $k_{p}$ and $k_{i}$ is obtained. Then, it is possible to plot the dependence of $k_{i}$ on $k_{p}$, which is the stability boundary $l\left(k_{p}, k_{i}, \omega\right)$ in the $\left(k_{p}, k_{i}\right)$-plane. The stability boundary divides the parameter plane into stable and unstable regions. The stable region is found by the choice of testing points inside the regions.
The method is very fast and effective, however, frequency rating becomes important. An efficient approach to avoid frequency rating can be obtained by using the Nyquist plot. It is only necessary to find real values of $\omega$ that satisfy

$$
\operatorname{Im}[G(j \omega)]=0
$$

\section{Stabilization of a plant with interval parametric uncertainty}

Consider a feedback system (Figure 1) with the PI controller (2) and the interval plant

$$
G(s, b, a)=\frac{N(s, b)}{D(s, a)}=\frac{b_{m} s^{m}+b_{m-1} s^{m-1}+\ldots+b_{0}}{a_{n} s^{n}+a_{n-1} s^{n-1}+\cdots+a_{0}}
$$

where $b_{i} \in\left[b_{i}^{-}, b_{i}^{+}\right], I=0,1,2, \ldots, m$ and $a_{j} \in\left[a_{j}^{-}, a_{j}^{+}\right]$, $j=0,1,2, \ldots, n$. Let the Kharitonov polynomials associated with $N(s, b)$ and $D(s, a)$ are (Barmish 1994):

$$
\begin{aligned}
& N_{1}(s, b)=b_{0}^{-}+b_{1}^{+} s+b_{2}^{+} s^{2}+b_{3}^{-} s^{3}+\ldots \\
& N_{2}(s, b)=b_{0}^{+}+b_{1}^{+} s+b_{2}^{-} s^{2}+b_{3}^{-} s^{3}+\ldots \\
& N_{3}(s, b)=b_{0}^{+}+b_{1}^{-} s+b_{2}^{-} s^{2}+b_{3}^{+} s^{3}+\ldots \\
& N_{4}(s, b)=b_{0}^{-}+b_{1}^{-} s+b_{2}^{+} s^{2}+b_{3}^{+} s^{3}+\ldots
\end{aligned}
$$

and

$$
\begin{aligned}
& D_{1}(s, b)=a_{0}^{-}+a_{1}^{+} s+a_{2}^{+} s^{2}+a_{3}^{-} s^{3}+\ldots \\
& D_{2}(s, b)=a_{0}^{+}+a_{1}^{+} s+a_{2}^{-} s^{2}+a_{3}^{-} s^{3}+\ldots \\
& D_{3}(s, b)=a_{0}^{+}+a_{1}^{-} s+a_{2}^{-} s^{2}+a_{3}^{+} s^{3}+\ldots \\
& D_{4}(s, b)=a_{0}^{-}+a_{1}^{-} s+a_{2}^{+} s^{2}+a_{3}^{+} s^{3}+\ldots
\end{aligned}
$$

By taking all combinations of the $N_{i}(s, b)$ and $D_{j}(s$, a) for $i, j=1,2,3,4$, the following family of sixteen Kharitonov plants can be obtained

$$
G_{K}(s)=G_{i j}(s)=\frac{N_{i}(s, b)}{D_{j}(s, a)}
$$

where $i, j=1,2,3,4 ; K=1, \ldots, 16$. The controller $C(s)$ (2) robustly stabilizes interval plant $G(s, b, a)$ if and only if it stabilizes each of the sixteen Kharitonov plants $G_{K}(s)$.

Define the set $S_{i j}\left(C(s) G_{i j}(s)\right)$, which contains all values of the parameters of the controller $C(s)$ which stabilizes $G_{i j}(s)$. The set $S_{i j}$ can be found using the approach described in the previous section. Then the set of all the stabilizing values of parameters of a PI controller, which stabilize the interval plant (12), can be written as

$$
\begin{aligned}
S\left(C(s) G_{K}(s)\right)= & S\left(C(s) G_{11}(s)\right) \cap S\left(C(s) G_{12}(s)\right) \cap \ldots \\
& \ldots \cap S\left(C(s) G_{44}(s)\right)
\end{aligned}
$$

\section{Experimental}

\section{Process Description}

Two counter-current tubular heat exchangers in series (Figure 2) represent the controlled process, 


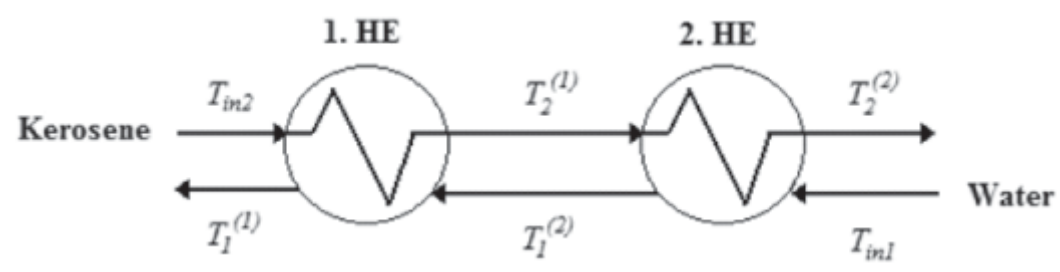

Fig. 2. Two counter-current tubular heat exchangers (HEs) in series.

in which kerosene as a product of the distillation in a refinery has to be cooled.

Kerosene flows in the inner tubes and the cooling water in the shell of the heat exchanger. The tubes of the heat exchangers are made from steel. The controlled variable is the temperature of the outlet stream of the kerosene from the $2^{\text {nd }}$ heat exchanger and the control input is the volumetric flow rate of the inlet stream of the cold water in the $2^{\text {nd }}$ heat exchanger. Two uncertain parameters are also considered in the heat exchangers. The heat-transfer coefficient changes as the flow rate of the cooling medium changes and the density of the kerosene depends on the temperature in the heat exchangers. Technological parameters and steady state values of the heat exchangers are summarized in the Table 1, where $n$ is the number of heat exchangers tubes, $l$ is the length of the heat exchanger, $d_{i n 1}$ is the inner diameter of the tube, $d_{\text {out } 1}$ is the outer diameter of the tube, $d_{i n 2}$ is the inner diameter of the heat exchanger, $A_{h}$ is the total heat transfer area, $V$ is the volume, $c_{p}$ is the thermal capacity, $\rho$ is the density, $T_{i n}$ is the input temperature, $q$ is the volumetric flow rate. The subscripts 1 and 2 refer to the water and kerosene, respectively. The superscripts (1)-(2) denote the associated heat exchangers property. The superscript $s$ denotes the steady state value.

Tab. 1. Technological parameters and steady states values of heat exchangers.

\begin{tabular}{lclc}
\hline Parameter & Value & Parameter & Value \\
\hline$n$ & 40 & $q_{1}^{s}\left[\mathrm{~m}^{3} \mathrm{~min}^{-1}\right]$ & 0.2891 \\
$l[\mathrm{~m}]$ & 6 & $T_{1}^{(1), s}\left[{ }^{\circ} \mathrm{C}\right]$ & 78.0 \\
$d_{\text {in1 }}[\mathrm{m}]$ & $19 \times 10^{-3}$ & $T_{1}^{(2), s}\left[{ }^{\circ} \mathrm{C}\right]$ & 43.4 \\
$d_{\text {out } 1}[\mathrm{~m}]$ & $25 \times 10^{-3}$ & $T_{2}^{(1), s}\left[{ }^{\circ} \mathrm{C}\right]$ & 112.3 \\
$d_{\text {in } 2}[\mathrm{~m}]$ & $414 \times 10^{-3}$ & $T_{2}^{(2), s}\left[{ }^{\circ} \mathrm{C}\right]$ & 66.6 \\
$A_{h}\left[\mathrm{~m}^{2}\right]$ & 16.6 & & \\
$V_{1}\left[\mathrm{~m}^{3}\right]$ & $91.2 \times 10^{-3}$ & & \\
$V_{2}\left[\mathrm{~m}^{3}\right]$ & $716.5 \times 10^{-3}$ & & \\
$c_{p 1}\left[\mathrm{~J} \mathrm{~kg}^{-1} \mathrm{~K}^{-1}\right]$ & $4.186 \times 10^{-3}$ & & \\
$c_{p 2}\left[\mathrm{~J} \mathrm{~kg}{ }^{-1} \mathrm{~K}^{-1}\right]$ & $2.140 \times 10^{-3}$ & & \\
$\rho_{1}\left[\mathrm{~kg} \mathrm{~m}^{-3}\right]$ & 980.0 & \\
$T_{\text {in } 1}\left[{ }^{\circ} \mathrm{C}\right]$ & 20.0 & \\
$T_{\text {in } 2}\left[{ }^{\circ} \mathrm{C}\right]$ & 180.0 & \\
$q_{2}\left[\mathrm{~m}^{3} \mathrm{~min}^{-1}\right]$ & 0.3498 & \\
\hline
\end{tabular}

The simplified dynamic model of the first heat exchanger is described by two linear differential equations

water:

$$
\begin{gathered}
q_{1} \rho_{1} c_{p 1} T_{1}^{(2)}(t)+A_{h} U \Delta \vartheta_{1}(t)= \\
=q_{1} \rho_{1} c_{p 1} T_{1}^{(1)}(t)+V_{1} \rho_{1} c_{p 1} \frac{d T_{1}^{(1)}(t)}{d t}, \\
T_{1}^{(1)}(0)=T_{1}^{(1), s}
\end{gathered}
$$

kerosene:

$$
\begin{gathered}
q_{2} \rho_{2} c_{p 2} T_{i n 2}-A_{h} U \Delta \vartheta_{1}(t)= \\
=q_{2} \rho_{2} c_{p 2} T_{2}^{(1)}(t)+V_{2} \rho_{2} c_{p 2} \frac{d T_{2}^{(1)}(t)}{d t}, \\
T_{2}^{(1)}(0)=T_{2}^{(1), s}
\end{gathered}
$$

where

$$
\Delta \vartheta_{1}(t)=\frac{\left(T_{\ln 2}-T_{1}^{(1)}(t)\right)+\left(T_{2}^{(1)}(t)-T_{1}^{(2)}(t)\right)}{2}
$$

The simplified dynamic model of the second heat exchanger is described similarly

water:

$$
\begin{gathered}
q_{1} \rho_{1} c_{p 1} T_{i n 1}(t)+A_{h} U \Delta \vartheta_{2}(t)= \\
=q_{1} \rho_{1} c_{p 1} T_{1}^{(2)}(t)+V_{1} \rho_{1} c_{p 1} \frac{d T_{1}^{(2)}(t)}{d t}, \\
T_{1}^{(2)}(0)=T_{1}^{(2), s}
\end{gathered}
$$

kerosene:

$$
\begin{gathered}
q_{2} \rho_{2} c_{p 2} T_{2}^{1}(t)-A_{h} U \Delta \vartheta_{2}(t)= \\
=q_{2} \rho_{2} c_{p 2} T_{2}^{(2)}(t)+V_{2} \rho_{2} c_{p 2} \frac{d T_{2}^{(2)}(t)}{d t}, \\
T_{2}^{(2)}(0)=T_{2}^{(2), s}
\end{gathered}
$$

where

$$
\Delta \vartheta_{2}(t)=\frac{\left(T_{2}^{(1)}(t)-T_{1}^{(2)}(t)\right)+\left(T_{2}^{(2)}(t)-T_{i n 1}\right)}{2}
$$

Minimal, maximal and nominal values of uncertain parameters are in Table 2, where $U$ is the heat transfer coefficient and $\rho_{2}$ is the density of kerosene. The nominal values of these parameters are the mean values of the intervals.

\section{Control of the Counter-Current Tubular Heat Exchangers}

The controlled variable is the temperature of the outlet stream of the kerosene from the $2^{\text {nd }}$ heat exchanger and the control input is the volumetric flow 
Tab. 2. Uncertain parameters in heat exchangers.

\begin{tabular}{lccc}
\hline Parameter & Minimal value & Nominal value & Maximal value \\
\hline$U\left[\mathrm{~J} \mathrm{~min}^{-1} \mathrm{~m}^{2} \mathrm{~K}^{-1}\right]$ & $2.777 \times 10^{4}$ & $2.893 \times 10^{4}$ & $3.008 \times 10^{4}$ \\
$\rho_{2}\left[\mathrm{~kg} \mathrm{~m}^{-3}\right]$ & 793.8 & 810.0 & 826.2 \\
\hline
\end{tabular}

rate of the inlet stream of the cold water in the $2^{\text {nd }}$ heat exchanger. For controller design, the mathematical model of the counter-current tubular heat exchangers in series with two uncertain parameters (Table 2) was obtained in the form of a transfer function

$$
G(s, b, a)=\frac{b_{2} s^{2}+b_{1} s+b_{0}}{a_{4} s^{4}+a_{3} s^{3}+a_{2} s^{2}+a_{1} s+a_{0}}
$$

where coefficients in the numerator and the denominator lie in following intervals: $b_{i} \in\left[b_{i}^{-}, b_{i}^{+}\right], i=0,1$, 2 and $a_{j} \in\left[a_{j}^{-}, a_{j}^{+}\right], j=0,1,2,3,4$. The values of the uncertain parameters are shown in Table 3.

Tab. 3. Uncertain parameters of transfer function (23).

\begin{tabular}{ccc}
\hline Parameter & Minimal value & Maximal value \\
\hline$b_{2}$ & -81.8929 & -69.7786 \\
$b_{1}$ & -394.0812 & -332.2067 \\
$b_{0}$ & -352.4606 & -305.4202 \\
$a_{4}$ & 1 & 1 \\
$a_{3}$ & 8.9019 & 9.0664 \\
$a_{2}$ & 24.5268 & 25.4822 \\
$a_{1}$ & 20.6756 & 21.9711 \\
$a_{0}$ & 5.1423 & 5.5674 \\
\hline
\end{tabular}

Then, combining of polynomials (13), (14) sixteen Kharitonov plants (15) are created and the approach described in the theoretical section is used for the robust PI controller design. Using (5) and (6) for (23) gives

$$
\begin{gathered}
a_{3} \omega^{4}-\left(a_{1}+b_{2} k_{i}+b_{1} k_{p}\right) \omega^{2}+b_{0} k_{i}=0 \\
a_{4} \omega^{4}-\left(a_{2}+b_{2} k_{p}\right) \omega^{2}+a_{0}+b_{0} k_{p}+b_{1} k_{i}=0
\end{gathered}
$$

From (24) and (25) PI controller parameters $k_{p}, k_{i}$ are calculated in dependence on the frequency $\omega$ according to (26) and (27)

$$
\begin{gathered}
k_{i}=\frac{\left(a_{3} b_{2}-a_{4} b_{1}\right) \omega^{6}+\left(a_{2} b_{1}-a_{1} b_{2}-a_{3} b_{0}\right) \omega^{4}}{b_{2}^{2} \omega^{4}+\left(b_{1}^{2}-2 b_{0} b_{2}\right) \omega^{2}+b_{0}^{2}}+ \\
+\frac{\left(a_{1} b_{0}-a_{0} b_{1}\right) \omega^{2}}{b_{2}^{2} \omega^{4}+\left(b_{1}^{2}-2 b_{0} b_{2}\right) \omega^{2}+b_{0}^{2}} \\
k_{p}=\frac{a_{3} \omega^{4}-\left(a_{1}+b_{2} k_{i}\right) \omega^{2}+b_{0} k_{i}}{b_{1} \omega^{2}}
\end{gathered}
$$

The region of all PI controller parameters, which are able to assure the robust stability of the feedback closed loop with the controlled systems (23) are found by the method, which is based on plotting the stability boundary in the $\left(k_{p}, k_{i}\right)$-plane. The region is found as the intersection of the stability regions obtained for 16 Kharitonov plants shown in Figure 3 .

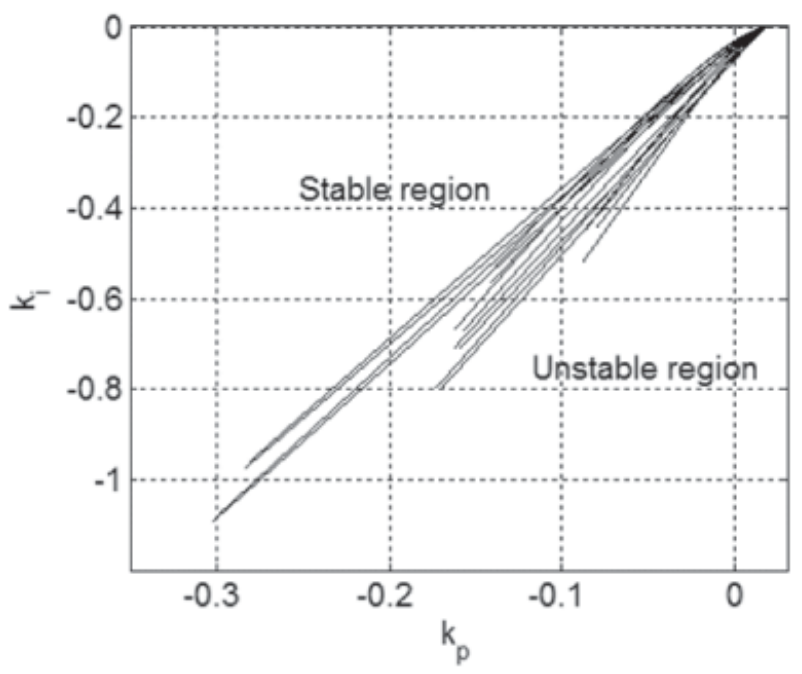

Fig. 3. Stability regions for $\omega \in(0 ; 2.7420)$.

The robust controller parameters $k_{p}$ and $k_{i}$ which stabilize all sixteen Kharitonov systems are chosen from the stable region and the designed PI controller is in the form

$$
C(s)=k_{p}+\frac{k_{i}}{s}=-0.3-\frac{0.2}{s}
$$

Figure 4a presents simulation results obtained during control of the model of the heat exchangers with the designed controller (28). The setpoint changes and disturbances are in Table 4 . The disturbances were represented by the step changes of the temperature of the inlet streams of water and kerosene $T_{i n 1}, T_{i n 2}$ and the volumetric flow rate of the kerosene $q_{2}$. Figure $4 \mathrm{~b}$ shows the control input.

\section{Conclusion}

The design of the robust PI controller for control of the counter-current tubular heat exchangers in series with two uncertain parameters is described in the paper. The approach for design of robust PI controllers is based on finding the stability boundary in the plane of controller parameters. 

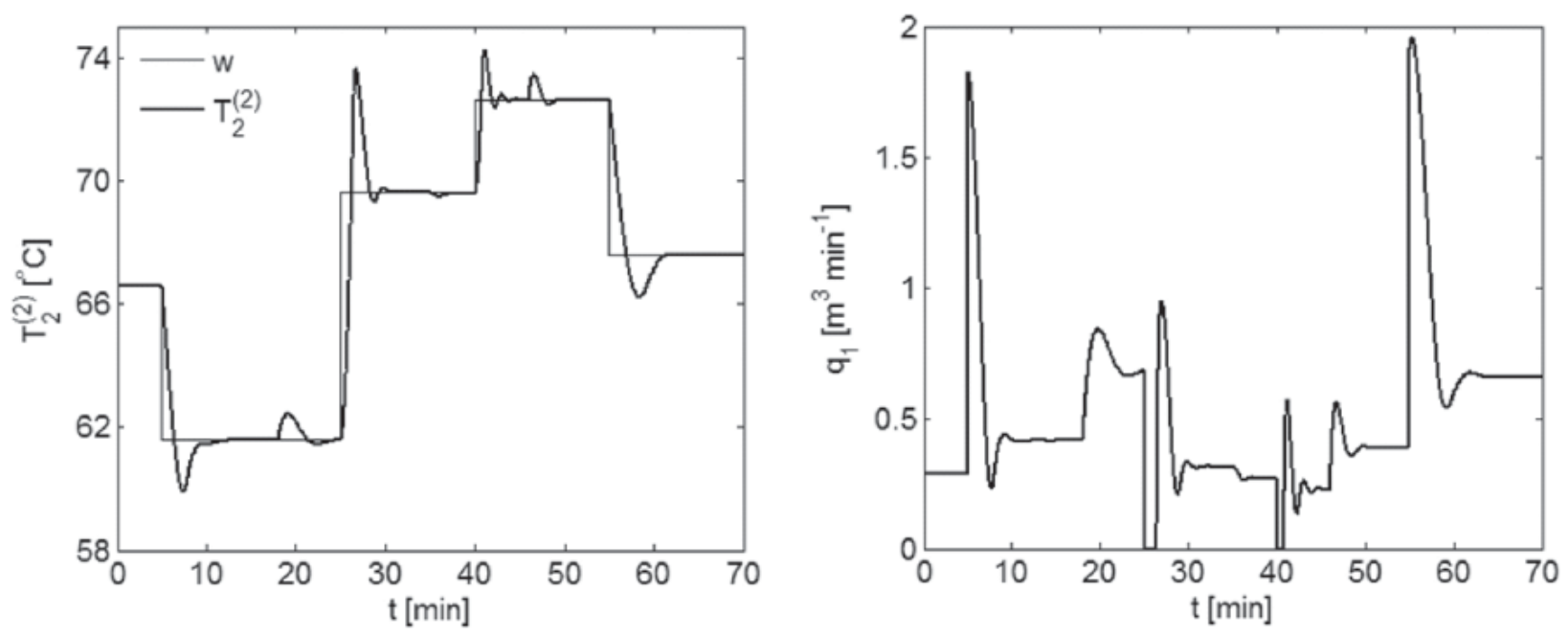

Fig. 4. a) Control responses of the temperature $T_{2}^{(2)}$ and b) control input $q_{1}$ generated by the robust PI controller (28).

Tab. 4. Simulation conditions.

\begin{tabular}{cccc}
\hline \multicolumn{2}{c}{ Setpoint changes } & \multicolumn{2}{c}{ Disturbances } \\
$\boldsymbol{t}$ [min $]$ & $\boldsymbol{T}_{2}^{(2)}\left[{ }^{\circ} \mathbf{C}\right]$ & & \\
\hline 5 & $66.6 \rightarrow 61.6$ & $t[\mathrm{~min}]$ & $T_{i n 1}\left[{ }^{\circ} \mathrm{C}\right]$ \\
25 & $61.6 \rightarrow 69.6$ & 18 & $20.0 \rightarrow 26.0$ \\
40 & $69.6 \rightarrow 72.6$ & $t[\mathrm{~min}]$ & $T_{i n 2}\left[{ }^{\circ} \mathrm{C}\right]$ \\
55 & $72.6 \rightarrow 67.6$ & 35 & $180.0 \rightarrow 172.0$ \\
& & $t[\mathrm{~min}]$ & $q_{2}\left[\mathrm{~m}^{3} \mathrm{~min}^{-1}\right]$ \\
& & 46 & $0.3498 \rightarrow 0.3998$ \\
\hline
\end{tabular}

Presented simulation results confirmed that the designed robust PI controller is able to assure the setpoint tracking and the disturbance rejection.

\section{Acknowledgement}

The authors gratefully acknowledge the contribution of the Scientific Grant Agency of the Slovak Republic under the grant 1/0973/12.

\section{References}

Barmish B (1994) New Tools for Robustness of Linear Systems. Macmillan Publishing Company, New York.
Abaoui MA, Vernières-Hassimi L, Seguin D, AbdelghaniIdrissi MA (2007) Applied Thermal Engineering, 27: 2332-2338.

Maidi A, Diaf M, Courriou J-P (2009) Journal of Process Control, 19: 297-313.

Nema PK, Datta AK (2006) International Journal of Heat and Mass Transfer, 49: 3360-3370.

Söylemez M, Munro N, Baki H (2003) Automatica, 39: $121-126$.

Tan N, Kaya I (2003) In Meditteranean Conference on Control and Automation, Rhodes, Greece.

Závacká J, Bakošová M, Vaneková K (2008) In $18^{\text {th }}$ International Congress of Chemical and Process Engineering, Prag, Czech Republic. 